\title{
Assessment of Frequency of Oral Conditions in Patients with Hematological Malignancies: A Hospital-Based Study
}

\author{
Rajeev Gupta ${ }^{1}$, Shveta Mahajan ${ }^{2}$, Jaskaran Singh ${ }^{3}$, Amit Dhawan ${ }^{4}$, Jaspreet Kaur ${ }^{5}$, Robin Kamboj ${ }^{6}$, \\ Gurjyot Singh Nanda? \\ ${ }^{1}$ Associate Professor, Department of Medicine, SGRDIMSR, Amritsar, Punjab, ${ }^{2}$ Dental Surgeon, JK Health Services, PHC \\ Lakhanpur, Jammu and Kashmir, ${ }^{3}$ Associate Professor, Department of ENT, SGRDIMSR, Amritsar, Punjab, ${ }^{4}$ Professor, Oral and \\ Maxillofacial surgery, SGRDIDSR, Amritsar, Punjab, ${ }^{5} 3$ rd year Post Graduate Student, Department of Medicine, SGRDIMSR, \\ Amritsar, Punjab, ${ }^{6} 3$ rd year Post Graduate Student, Department of Medicine, SGRDIMSR, Amritsar, Punjab, ${ }^{73}$ rd year Post \\ Graduate Student, Department of Medicine, SGRDIMSR, Amritsar, Punjab, India.
}

Corresponding author: Dr Rajeev Gupta, Associate Professor, Department of Medicine, SGRDIMSR, Amritsar, Punjab, India

DOI: http://dx.doi.org/10.21276/ijcmsr.2019.4.4.48

How to cite this article: Rajeev Gupta, Shveta Mahajan, Jaskaran Singh, Amit Dhawan, Jaspreet Kaur, Robin Kamboj, Gurjyot Singh Nanda. Assessment of frequency of oral conditions in patients with Hematological Malignancies : a hospital-based study. International Journal of Contemporary Medicine Surgery and Radiology. 2019;4(4):D200-D205.

\section{A B S T R A C T}

Introduction: Due to infiltration of leukemic cells or due to associated decline in normal marrow elements, especially in the acute phase of leukaemia, the early signs of leukaemia can be observed in the oral cavity, as common lesions at this stage of the disease can be screened and diagnosed by the cancer specialist with the help of a dentist. Therefore, the medical and dental community should be trained about the oral manifestations of Hematological Malignancies and oral complications of anticancer treatment. This can eliminate the oral symptoms of the disease and to improve quality of life for these patients. Hence, the aim of the present study was to assess the frequency of oral conditions in patients with Hematological Malignancies .

Material and methods: The present study was a cross-sectional study which was conducted among 348 patients attending the tertiary care hospital. Details related to clinical factors were collected from routine examinations through electronic medical records and data related to oral examination and general eaxamination including blood test and biopsy were recorded on a standard proforma which included patient identification, demographic information, underlying disease, reason for hospitalization and the drugs included in chemotherapy.

Results: In the present study, the majority of the patients had multiple myeloma i.e. about $48(32 \%)$ and the least i.e. 1 $(0.6 \%)$ had chronic myeloid leukaemia followed by acute myeloid leukaemia in 36 (24\%), sickle cell anaemia in 14(9.3\%), hodgkin's lymphoma in 10(6.6\%) and lymphoblastic lymphoma in 12 (8\%). About 11(7.3\%) patients had plasmacytoma followed by chronic lymphocytic leukaemia in 2(1.3\%) and thrombocytopenic purpura in $4(2.6 \%)$.

Conclusion: Multidisciplinary team is needed in which cancer specialists along with dentists should be incorporated so that preventive measures can be achieved for the patients with haematological disorders and oral conditions together.

Keywords: Leukaemia, Frequency, Hospital-Based, Haematology, Oral Manifestations

\section{INTRODUCTION}

Leukaemia is a general term used for a group of malignant hematologic disorders arising from hematopoietic stem cells and characterized by disorganized proliferation of neoplastic cells. Historically, leukaemia were broadly classified into 4 main categories based on the origin of the blood cell (myeloid versus lymphoid) and disease characteristics (acute versus chronic). Advances in understanding of molecular, histomorphologic, and genetic changes have resulted in a new classification for acute leukaemia (AL). ${ }^{1}$

Before initiating invasive dental procedures, in all the phases of oral health care, there is no absolute minimum platelet or neutrophil counts needed. It is suggested that when the platelet count is less than 50,000 to 60,000 per cubic millimetre $\left(\mathrm{mm}^{3}\right)$, a platelet transfusion may be performed before surgical procedures, and a neutrophil count less than 500 to 2,000 cells per $\mathrm{mm}^{3}$ might require antibiotic prophylaxis. Similarly, if the neutrophil count is less than 1,000 cells per $\mathrm{mm}^{3}$, elective treatment should be postponed, and emergency treatment along with antibiotic coverage should be discussed with the medical and oncologist team. Dentists are generally trained that oral cavity is a common location for signs and symptoms of leukaemia and may be related to the disease. ${ }^{2,3}$

The first signs of hematologic diseases may be oral lesions. To maintain the balance of whole body, oral conditions should never be ignored as it is important for systemic balance. Oral conditions with general diseases are treated at correct time then patient's quality of life and cost of treatment along with 
longer stay in hospital can be reduced to a great extent. ${ }^{4}$

Chemotherapy is found to be the most important treatment in all types of leukaemia but this treatment modality is necessarily associated with systemic or local adverse effects on healthy tissues. The oral manifestations are influenced by factors including the type, dosage, duration, and schedule of administration of chemotherapeutic agents; patient age; deficient oral hygiene; and pre-existing periodontal disease which is associated with chemotherapy. These factors, in turn, influence the incidence of mucositis, decreased salivary flow, pain, opportunistic infections like candidiasis of oral mucosal regions and gingival bleeding. ${ }^{5}$

Some of the examples of oral manifestation of a hematologic problem are petechiae or ecchymosis, and spontaneous gingival bleeding without a local cause. The oral manifestations of patients with hematologic diseases can occur due to the disease itself or as a consequence of treatment. Anaemia, clotting disorders or neoplasms is some of the signs of hematologic diseases. Moreover, paleness of the oral mucosa and ulcers are associated with anaemia and gingival overgrowth and persistent infections may be signs of leukaemia. The treatment of hematologic diseases includes chemotherapy, radiotherapy, and hematopoietic stem cell transplantation (HSCT). ${ }^{6,7}$

Depending on the type and dosage of medications, chemotherapy and the conditioning regimen for HSCT have many deleterious effects on the oral tissues. Oral mucositis, a common side effect of chemotherapy, causes severe pain, which is only relieved by opioids. It appears sometimes as a generalized erythema and evolved into painful pseudomembranous ulcers. Malignant cells are the target of antineoplastic drugs, but the oral epithelium and other cells with high mitotic rates are usually affected by the treatment. The most common adverse effect of treatment is neutropenia and thrombocytopenia, leaving patients more susceptible to oral bleeding, infections and ulcerations. An adverse effect of treatment is oral mucosal pigmentation. ${ }^{8,9}$

In the early and late period after HSCT, complications can affect most of the organs with oral tissues being affected. A late complication of HSCT that affects nearly $80 \%$ of the patients is the oral chronic graft-versus-host disease. The most common oral complications in the treatment of hematologic diseases are mucositis, bleeding, hyposalivation, fungal or viral infections and aggravation of odontogenic infections. Salivary flow rates are often reduced due to chemotherapy or to chronic graft-versus-host disease and may cause many oral complications, such as varying degrees of discomfort, dysphagia, dysphasia, dysgeusia, halitosis, and infections such as dental decay, periodontitis and candidiasis. ${ }^{10}$

Leukaemia is a general term for a group of malignant hematologic disorders arising from hematopoietic stem cells and characterized by disorganized proliferation of neoplastic cells. It has been found that underlying conditions of leukaemia can lead to occurrence of oral manifestations as they can lead to oral manifestations such as gingival bleeding, hyperplasia, opportunistic infections and bone alterations are found to be the most common oral manifestations of leukaemia. ${ }^{11}$

Multi agent chemotherapy and radiation therapy have greatly increased the chances of survival and are widely accepted. However, these treatment modalities can lead to the most common oral complication that has an impact on the developing dentition and on orofacial growth. Clinicians should be able to clearly recognize oral manifestations of leukaemia. All the preventive and curative oral measures should be carried out with the consultation of haematologist or podiatrist oncologist in charge. ${ }^{12,13}$

As observed from the previous literature, oral complications at this stage included mucositis, gingival bleeding, oral candidiasis, herpes simplex, xerostomia and bacterial infections. Chemotherapy-associated oral mucositis occurs due to interference with epithelial cell turnover and induction of apoptosis. The indirect cytotoxic effects of the release of inflammatory mediators, loss of protective salivary components, and treatment-induced neutropenia have been noted as contributors to the development of oral mucositis. Furthermore, chemotherapeutic agents such as fluorouracil, methotrexate, daunorubicin, and cyclophosphamide, which are commonly used in ALL treatment protocols, are particularly toxic to the oral mucosa. ${ }^{14,15}$

Dentists also plays an important role to clearly recognize oral manifestations of leukaemia as sometimes they sometimes are the first care health professional that discovers acute leukaemia in children. These approaches may prevent associated life threatening situations orally and systemically which promotes rapid and complete mucosal healing, alleviates pain and improves quality of life in patients with leukaemia. ${ }^{16}$ Hence, the aim of the present study was to assess the frequency of oral conditions in patients with Hematological Malignancies attending the tertiary care hospital.

\section{MATERIAL AND METHODS}

The present study was a cross-sectional study which was conducted among patients attending the ward tertially care hospital in Punjab, North India. Data used in this study were collected from routine oral examinations which was conducted weekly from May 2019 to December 2019 among the patients of this ward. All the patients willing to be examined were included in this study, even if they did not had complaint about any present condition. Initially informed written consent was obtained from the patients as after getting permission from Institutional review board of the hospital. Those patients who were unable to undergo oral examination due to the any reason like sedation or intubation were completely excluded from this study. Details related to clinical factors were collected from routine examinations through electronic medical records and data related to oral examination were recorded on a standard proforma which included patient identification, demographic information, underlying disease, reason for hospitalization and the drugs included in chemotherapy.

A team of five cancer specialist and three general dentists were involved in the oral and general examination examination of the patients. Blood investigation and biopsy was done to examine the patients for leukemia. The diagnosis of chronic lymphocytic leukaemia requires the presence of at least $5 \times$ 109 B lymphocytes/L (5000/_L) in the peripheral blood. The 
clonality of the circulating B lymphocytes can be detected with the help of the procedure called as flow cytometry. The leukaemia cells found in the blood smear are small, mature lymphocytes with a narrow border of cytoplasm and a dense nucleus lacking discernible nucleoli and having partially aggregated chromatin. These cells may be found admixed with upto $55 \%$ of the blood lymphocytes with larger or atypical cells, which are cleaved cells, or prolymphocytes.

The diagnosis related to oral diseases was based on laboratory exams when required. Training was provided for the two general dentists by exhibiting images of normal mucosa and its variations with clinical discussion on the differential diagnosis of oral lesions. If oral changes were seen, the medical team was informed and the patient was sent to the stomatologist of the Oral Health Program team of the same hospital. The intra-oral examination was performed at the bed side with the aid of a frontal light emitting diode light, while respecting biosafety guidelines and principles of oral semiology.

The following conditions were considered such as bleeding disorders, dry lips or mucosa, fungal or viral infections and aggravation of odontogenic infections. The oral mucosa was evaluated in the following order as vermillion lip border,labial mucosa, buccal mucosa, gingiva, tongue (dorsum, lateral and ventral surfaces), hard and soft palate and oropharynx on both sides of the mouth.

\section{STATISTICAL ANALYSIS}

The data was entered into the Microsoft excel sheet and was analyzed with the help of SPSS software version 21. The descriptive statistics was performed such as percentage and frequency distribution and was presented in the form of tables, graphs and pie-charts.

\section{RESULTS}

In the present study, the majority of the patients had multiple myeloma i.e. about $48(32 \%)$ and the least i.e. $1(0.6 \%)$ had chronic myeloid leukaemia followed by acute myeloid leukaemia in $36(24 \%)$, sickle cell anaemia in 14(9.3\%), hodgkin's lymphoma in $10(6.6 \%)$ and lymphoblastic lymphoma in $12(8 \%)$. About $11(7.3 \%)$ patients had plasmacytoma followed by chronic lymphocytic leukaemia in $2(1.3 \%)$ and thrombocytopenic purpura in $4(2.6 \%)$. The

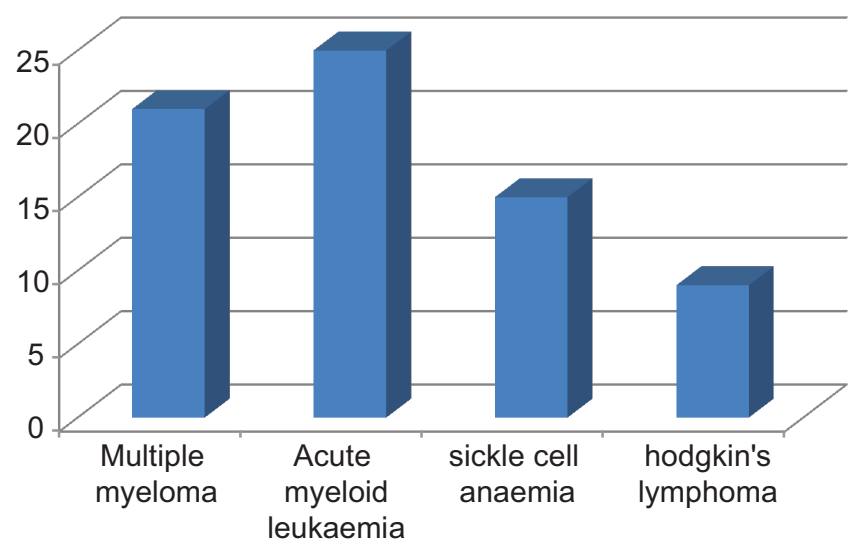

Graph-1: Shows the distribution of data based on oral conditions according to the most underlying diseases reasons for hospitalization was chemotherapy or disease complication in $124(82.6 \%)$, relapse was observed in $21(14 \%)$ of the patients. Pre-transplant was seen in 5(3.3\%) patients (Table 1). It was found that there was no history observed related to hematopoietic stem cell transplantation in 122 (81.3\%) patients, about 18 (12\%) patients being prepared for hematopoietic stem cell transplantation. Allogenic hematopoietic stem cell transplantation was seen in 6(4\%) patients and $4(2.6 \%)$ in autologous hematopoietic stem cell transplantation (Table 1).

In the current study, dry lips was seen in $10(25.7 \%)$ of the patients followed by mucositis in 10 (14.2\%) and petechiae

\begin{tabular}{|l|l|l|}
\hline Characteristic & Frequency & Percentage \\
\hline Multiple myeloma & 48 & $32 \%$ \\
\hline Acute myeloid leukaemia & 36 & $24 \%$ \\
\hline Sickle cell anaemia & 14 & $9.3 \%$ \\
\hline Hodgkin's lymphoma & 10 & $6.6 \%$ \\
\hline Lymphoblastic lymphoma & 12 & $8 \%$ \\
\hline Mantle cell lymphoma & 2 & $1.3 \%$ \\
\hline Chronic myeloid leukaemia & 1 & $0.6 \%$ \\
\hline Myelodydplasia & 2 & $1.3 \%$ \\
\hline Thrombocytopenic purpura & 4 & $2.6 \%$ \\
\hline Plasmacytoma & 11 & $7.3 \%$ \\
\hline Chronic lymphocytic leukaemia & 2 & $1.3 \%$ \\
\hline Large cell lymphoma & 4 & $2.6 \%$ \\
\hline Others & 4 & $2.6 \%$ \\
\hline Reasons for hospitalization & & \\
\hline $\begin{array}{l}\text { Chemotherapy or disease compli- } \\
\text { cations }\end{array}$ & 124 & $82.6 \%$ \\
\hline Relapse & 21 & $14 \%$ \\
\hline Pre-transplant & 5 & $3.3 \%$ \\
\hline Transplant status & 122 & $81.3 \%$ \\
\hline No history of HSCT & 18 & $12 \%$ \\
\hline Patients being prepared for HSCT & 6 & $4 \%$ \\
\hline Allogeneic HSCT & 4 & $2.6 \%$ \\
\hline Autologous HSCT & \\
\hline HSCT: hematopoietic stem cell transplantation \\
\hline Table-1: Shows the distribution of data based on the clinical \\
\hline
\end{tabular}

\begin{tabular}{|l|c|c|}
\hline Oral changes & $\mathbf{n}^{\mathbf{a}}$ & Percentage \\
\hline Dry lips & 18 & $25.7 \%$ \\
\hline Mucositis & 8 & $11.4 \%$ \\
\hline Petechiae & 6 & $8.57 \%$ \\
\hline Candidiasis & 10 & $14.2 \%$ \\
\hline Gingival bleeding & 7 & $10 \%$ \\
\hline Herpes Simplex & 5 & $7.14 \%$ \\
\hline Aggravation of odontogenic infection & 4 & $5.7 \%$ \\
\hline Ulcers & 8 & $11.4 \%$ \\
\hline Zygomycosis & 4 & $5.7 \%$ \\
\hline Total & 70 & $100 \%$ \\
\hline $\begin{array}{l}\text { Some patients were observed with more than one oral condi- } \\
\text { tion }\end{array}$ \\
\hline $\begin{array}{l}\text { Table-2: Shows the distribution of data based on oral condi- } \\
\text { tions associated to the underlying disease or chemotherapy } \\
\text { observed in the patients }\end{array}$ \\
\hline
\end{tabular}




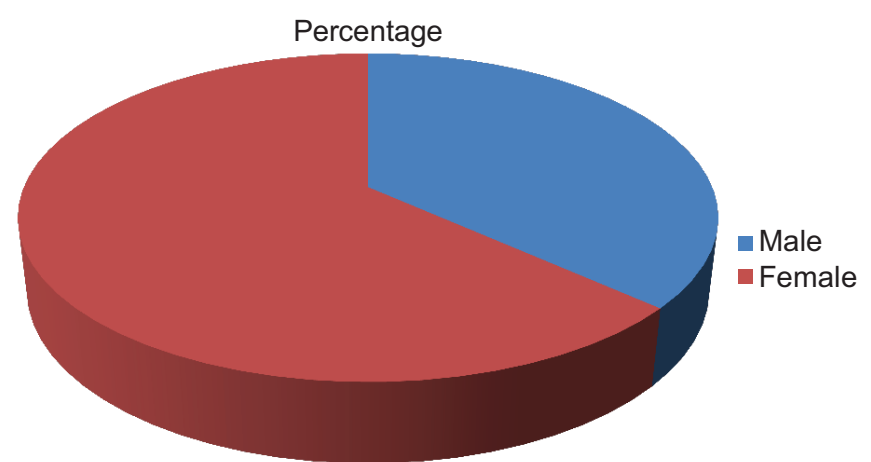

Pie chart-1: Shows the distribution of data based on gender among the study subjects

\begin{tabular}{|l|l|l|}
\hline Oral changes & $\mathbf{n}^{\mathbf{a}}$ & Percentage \\
\hline Frictional keratosis & 16 & $42.1 \%$ \\
\hline Traumatic ulcer & 6 & $15.7 \%$ \\
\hline Reactive fibrous hyperplasia & 4 & $10.5 \%$ \\
\hline leukoplakia & 3 & $7.8 \%$ \\
\hline Aphthous ulcer & 2 & $5.2 \%$ \\
\hline Coated tongue & 4 & $10.5 \%$ \\
\hline Mucocele & 2 & $5.2 \%$ \\
\hline Lipoma & 1 & $2.6 \%$ \\
\hline Total & 38 & $100 \%$ \\
\hline $\begin{array}{l}\text { Table-3: Shows the distribution of data based on oral condi- } \\
\text { tions not related to the underlying disease observed among } \\
\text { patients }\end{array}$ \\
\hline
\end{tabular}

in $6(8.57 \%)$. Candidiasis was observed in $8(11.4 \%)$ patients followed by gingival bleeding in $7(10 \%)$ patients and herpes simplex in $5(7.14 \%)$ patients. About $8(11.4 \%)$ patients had ulcers and $4(5.7 \%)$ had aggravation of odontogenic infection and zygomycosis (Table 2).

In Table 3, it was found that frictional keratosis was seen in maximum number of the patients i.e. in 16(42.1\%) and traumatic ulcer in 6(15.7\%) patients (Table 3 ). The majority of the patients had oral conditions related to the most underlying disease was acute myeloid leukaemia in 25(35.7\%) followed by multiple myeloma $21(30 \%) 15(21.4 \%)$ and sickle cell anaemia (Graph 1). Out of 150 patients about 55 (36.6) were males and 95(63.3\%) were females. (Pie chart 1)

\section{DISCUSSION}

Leukaemia is caused by a malignant proliferation of white blood cell (WBC) precursors. It is a type of cancer which affects the bone marrow and peripheral blood. In the leukemic state, WBC-forming cells, including myeloid and/or lymphoid cells, exhibit hyperplastic changes and produce immature or abnormal WBCs, which leads to the deterioration of normal hematopoietic function. Leukaemia is divided clinically into acute and chronic forms, and acute leukaemia can be fatal within a few days if not treated properly. ${ }^{17}$ It has been generally accepted in the literature and authoritative textbooks that dental patients with Leukaemia commonly have oral signs of undiagnosed leukaemia that could be identified by the prudent dental practitioner, including gingival bleeding, gingival enlargement, oral petechiae, and acute oral infections. ${ }^{18}$
The dental management of patients with leukaemia is necessarily embedded in a multidisciplinary context, because the medical complexity that this patient presents may interfere in the determination of priorities and the time available for dental treatment. For the US National Cancer Institute, the multidisciplinary team should have oncologists, nurses, dentists along with general and stomatological practitioners accompanied with social workers, nutritionists, and other health professionals, which may contribute to the prevention and treatment of oral complications in these patients. ${ }^{19,20}$

The oral health condition may interfere in morbidity and disease prognosis. Oral infections can be a source of bacteraemia that sometimes complicates the prognosis; infections of different etiologies occurred in $16.4 \%$ of the patients in this study. Infections related to antineoplastic chemotherapy have been reported in $70 \%$ of the patients submitted to immunosuppression. Oral bacterial infections are not always easy to identify because patients do not present the classic signs; there are no usual signs of abscess or suppuration because leukocytes are reduced in neutropenic patients. Therefore, fever may be the only sign of the infection. Of the cases, $2.5 \%$ were diagnosed as exacerbations of bacterial odontogenic infections. ${ }^{21,22,23}$

A detailed dental examination was performed which was not the aim of this approach. It was observed that patients were identified with the oral diseases and then were referred to team of dentists involved in an oral health program initiative carried out by the institution. Before starting the chemotherapy, the extraction or treatment of infected teeth was planned as abnormal bleeding, insufficient wound healing and local infection can minimize the chances for the treatment given in haematological diseases. ${ }^{24}$

Oral candidiasis is the most frequent fungal infection found in the oral cavity. It may be characterized as pseudomembranous white plaques, erythematous areas, chronic atrophic white plaques followed by angular cheilitis. It is rarely seen in immuno-competent patients. Colonization of candida species was detected in $26 \%$ of the patients with terminal cancer but clinical findings showed angular cheilitis in 11\% and pseudomembranous candidiasis in $9 \%$. In the present study, $14.2 \%$ presented oral candidiasis with all diagnoses being confirmed by culture. ${ }^{25}$

According to the study done by Gomes AOF et al it was found that dry lips were the most common oral condition (12.6\%). On considering only those patients who underwent chemotherapy, $31.3 \%$ of the patients suffered from dry lips. Patients with dry lips often complain of xerostomia and these finding are in concordance with the finding of the present study. There was no sialometry present as part of the routine oral exam of the patients on the ward. Xerostomia and hyposalivation are frequent side effects of chemotherapy. ${ }^{26}$

It was found from the literature that xerogenic drugs such as diuretics, antihypertensive and anti-histamine drugs were administered to the patients in this study. Dry lips found was may be aggravated due to use of air conditioning among hospital wards leading to dry environment. ${ }^{27}$ This study presents some limitations such as there was some missing information on patient's records which was a common 
problem in retrospective studies. Furthermore, to evaluate the oral tissues, bedside examinations were also restricted to clinical findings, with no imaging resources, précised periodontal instruments or any other auxiliary instruments. Whenever an additional exam was required, the patients were referred to the clinic. As per our knowledge, this study is the first in which an examination directed at detecting the oral manifestations of leukaemia in patients of Northern part of India were used so detailed comparison with other studies could not be made.

\section{CONCLUSION}

This study showed that it is very important to diagnose the oral conditions among haematology patients at correct time for the prevention and also in planning the appropriate treatment regime for the haematological disorders. Oral hygiene habits play a relevant role in preserving or improving the overall health of the child. Combination of oncology team and dentists will help in complete eradication of the lack of awareness among the public. Hence, guidance, encouragement and proper follow-up of oral health in these patients can be of paramount importance in the prevention or mitigation of the oral complications of antineoplastic therapy.

\section{REFERENCES}

1. Neville BW, Damm DD, Allen CM, Chi AC. Hematologic disorders. In: Neville BW, ed. Oral and Maxil- lofacial Pathology. 4th ed. St. Louis, MO: Elsevier Saunders; 2015:533-560.

2. Zimmermann C, Meurer MI, Grando LJ, Gonzaga Del Moral JA, da Silva Rath IB, Schaefer Tavares S. Dental treatment in patients with leukemia. J Oncol. 2015: 571739 .

3. Gupta A, Epstein JB, Cabay RJ. Bleeding disorders of importance in dental care and related patient management. J Can Dent Assoc. 2007;73(1):77-84.

4. Francisconi CF, Caldas RJ, Oliveira Martins LJ, Fischer Rubira CM, da Silva Santos PS. Leukemic oral manifestations and their management. Asian Pac J Cancer Prev. 2016; 17(3):911-5.

5. Franch AM, Esteve CG, Pérez MGS. Oral manifestations and dental management of patient with leukocyte alterations. J Clin Exp Dent. 2011; 3 (1):53-59.

6. Gudiol C, Garcia-Vidal C, Arnan M, SanchezOrtega I, Patino B, Duarte R, et al. Etiology, clinical features and outcomes of pre-engraftment and postengraftment bloodstream infection in hematopoietic stem cell transplantation recipients. Bone Marrow Transplant. 2014; 49(6):824-30.

7. Jhamb T, Syed AZ, Baur D. Recognizing oral manifestations of multiple myeloma.J Mass Dent Soc. 2015; 64(1):18-9.

8. Grgic Medic M, Gornik I, Gasparovic V. Hematologic malignancies in the medical intensive care unitoutcomes and prognostic factors. Hematology. 2015; 20(5):247-53.

9. Adeyemo TA, Adeyemo WL, Adediran A, Akinbami
AJ, Akanmu AS. Orofacial manifestation of hematological disorders: hemato-oncologic and immuno-deficiency disorders. Indian J Dent Res. 2011; 22(5):688-97.

10. Bennett M. Pain management for chemotherapyinduced oral mucositis. Nurs Child Young People. 2016; 28(10):25-9.

11. Amadori F, Bardellini E, Conti G, Pedrini N, Schumacher RF, Majorana A. Low-level laser therapy for treatment of chemotherapy-induced oral mucositis in childhood: a randomized double-blind controlled study. Lasers Med Sci. 2016; 31(6):1231-6.

12. Leppla L, De Geest S, Fierz K, Deschler-Baier B, Koller A. An oral care self-management support protocol (OrCaSS) to reduce oral mucositis in hospitalized patients with acute myeloid leukemia and allogeneic hematopoietic stem cell transplantation: a randomized controlled pilot study. Support Care Cancer. 2016; 24(2):773-82.

13. Critchlow D. Part 3: Impact of systemic conditions and medications on oral health. Br J Community Nurs. 2017; 22(4):181-90.

14. Figliolia SL, Oliveira DT, Pereira MC, Lauris JR, Mauricio AR, Oliveira DT, Mello de Andrea ML. Oral mucositis in acute lymphoblastic leukaemia: analysis of 169 paediatric patients. Oral Dis. 2008; 14 (8):761-766.

15. Chaveli-Lopez B. Oral toxicity produced by chemotherapy: A systematic review. J Clin Exp Dent. 2014; 6 (1):81-90.

16. Khosla J, Yeh AC, Spitzer TR, Dey BR. Hematopoietic stem cell transplant-associated thrombotic microangiopathy: current paradigm and novel therapies. Bone Marrow Transplant. 2018; 53(2):12937.

17. Wolff A, Joshi RK, Ekstrom J, Aframian D, Pedersen AM, Proctor G, et al. Guide to medications inducing salivary gland dysfunction, xerostomia, and subjective sialorrhea: a systematic review sponsored by the World Workshop on Oral Medicine VI. Drugs R D. 2017; 17(1):1-28.

18. Little JW, Falace DA, Miller CS, Rhodus NL. Manejo Odontológico do Paciente Clinicamente Comprometido. 7a ed. Rio de Janeiro: Elsevier; 2008.

19. Akashi M, Shibuya Y, Kusumoto J, Furudoi S, Inui Y, Yakushijin K, et al. Myelosuppression grading of chemotherapies for hematologic malignancies to facilitate communication between medical and dental staff: lessons from two cases experienced odontogenic septicemia. BMC Oral Health. 2013; 13:41.

20. Nogueira-Filho G, Tenenbaum HC. So why do we call it the oral-systemic health connection? J Can Dent Assoc. 2011; 77: 36.

21. Elad S, Zadik Y, Yarom N. Oral complications of nonsurgical cancer therapies. Atlas Oral Maxillofac Surg Clin North Am. 2017; 25(2):133-47.

22. Epstein JB, Beier Jensen S. Management of hyposalivation and xerostomia: criteria for treatment strategies. Compend Contin Educ Dent. 2015; 
36(8):600-3.

23. Sakaguchi H. Treatment and prevention of oral candidiasis in elderly patients. Med Mycol J. 2017; 58(2):J43- J49.

24. Telles DR, Karki N, Marshall MW. Oral fungal infections: diagnosis and management. Dent Clin North Am. 2017; 61(2):319-49.

25. Djuric M, Jankovic L, Jovanovic T, Pavlica D, Brkic S, Knezevic A, et al. Prevalence of oral herpes simplex virus reactivation in cancer patients: a comparison of different techniques of viral detection. J Oral Pathol Med. 2009; 38(2):167-73.

26. Gomes AOF. The frequency of oral conditions detected in hematology inpatients. Hematol Transfus Cell Therr. 2018; 40(3):240-244.

27. Torres SR. Saldo Positivo para a Campanha de Prevenc, ão em Estomatologia. J Assoc Bras Odontol. 2003; 60(1):24-5.

Source of Support: Nil; Conflict of Interest: None

Submitted: 11-08-2019; Accepted: 10-09-2019; Published online: 12-11-2019 